Short communication

\title{
Proteomic responses reveal the differential effects induced by cadmium in mussels Mytilus galloprovincialis at early life stages
}

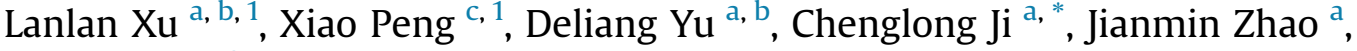 \\ Huifeng $\mathrm{Wu}^{\text {a }}$ \\ ${ }^{a}$ Key Laboratory of Coastal Zone Environmental Processes, Yantai Institute of Coastal Zone Research (YIC), Chinese Academy of Sciences (CAS), Shandong \\ Provincial Key Laboratory of Coastal Zone Environmental Processes, YICCAS, Yantai, 264003, PR China \\ ${ }^{\mathrm{b}}$ University of Chinese Academy of Sciences, Beijing, 100049, PR China \\ ${ }^{\mathrm{c}}$ Key Laboratory of Optoelectronic Devices and Systems of Ministry of Education and Guangdong Province, College of Optoelectronic Engineering, Shenzhen \\ University, Shenzhen, 518060, PR China
}

\section{A R T I C L E I N F O}

\section{Article history:}

Received 12 April 2016

Received in revised form

10 June 2016

Accepted 11 June 2016

Available online 11 June 2016

\section{Keywords:}

Mytilus galloprovincialis

Cadmium

Biological effects

Proteomics

\begin{abstract}
A B S T R A C T
Cadmium (Cd) has become an important metal contaminant and posed severe risk on the organisms in the coastal environments of the Bohai Sea. Marine mussel Mytilus galloprovincialis is widely distributed along the Bohai coast and consumed as seafood by local residents. Evidences indicate that the early stages of marine organisms are more sensitive to metal contaminants. In this study, we applied twodimensional electrophoresis-based proteomics to characterize the biological effects of $\mathrm{Cd}\left(50 \mu \mathrm{g} \mathrm{L}^{-1}\right)$ in the early life stages (D-shape larval and juvenile) of mussels. The different proteomic responses demonstrated the differential responsive mechanisms to $\mathrm{Cd}$ exposure in these two early life stages of mussels. In details, results indicated that $\mathrm{Cd}$ mainly induced immune and oxidative stresses in both Dshape larval and juvenile mussels via different pathways. In addition, the significant up-regulation of triosephosphate isomerase and metallothionein confirmed the enhanced energy demand and mobilized detoxification mechanism in D-shape larval mussels exposed to $\mathrm{Cd}$. In juvenile mussels, $\mathrm{Cd}$ exposure also induced clear apoptosis. Overall, this work suggests that $\mathrm{Cd}$ is a potential immune toxicant to mussel M. galloprovincialis at early life stages.
\end{abstract}

() 2016 Elsevier Ltd. All rights reserved.

\section{Introduction}

Because of the industrial discharge from numerous metal smelteries, cadmium (Cd) has become an important metal contaminant in the marine and coastal environments along the Bohai Sea. Sun et al. reported that Cd posed prominent risk on the marine organisms and ecosystem due to the high concentrations of $\mathrm{Cd}$ in the sediments from the Bohai coast [1]. Our recent research indicated that the dominant species, shrimp Crangon affinis, was contaminated by $\mathrm{Cd}$ from the Yellow River Estuary along the Bohai Sea [2]. As it is known, Cd can induce multiple adverse effects in organisms. It may induce oxidative stress in organisms by producing excessive reactive oxygen species [3]. Additionally, Cd can disturb the energy metabolism in clam Ruditapes philippinarum

\footnotetext{
* Corresponding author.

E-mail address: clji@yic.ac.cn (C. Ji).

1 These two authors contributed equally to this work.
}

indicated by the enhanced anaerobic metabolism [4]. Since Cd has become one of the most severe metal contaminants in the Bohai Sea, it is necessary to characterize the biological effects of $\mathrm{Cd}$ in marine animals.

The traditional biological approaches basically focus on the test of specific responses, such as the selected gene expression patterns or enzyme activities, to characterize the biological effects of environmental stressors in organisms [5,6]. In recent years, the "-omic" approaches including genomics, transcriptomics, proteomics and metabolomics have been widely used in environmental biology [7-11]. Among these approaches, two-dimensional electrophoresis (2DE)-based proteomics is useful to present complex biologically functional protein networks [12]. Not only is proteomics a powerful tool for describing complete proteomes at organelle, cell, organ or tissue levels, but it can also be used to detect the minor proteomic responses in biological samples under different conditions [13].

Marine mussels are ubiquitous, sedentary filter-feeders that play critical roles in maintaining marine ecosystem health. This species can accumulate high amounts of contaminants from marine 
and coastal environments and therefore is used to monitor marine and coastal environmental contaminants [14]. The mussel Mytilus galloprovincialis is widely distributed along the Bohai coast and popularly consumed as seafood by local residents. In this study, mussel M. galloprovincialis was used as the experimental animal to investigate the biological effects of $\mathrm{Cd}$. However, evidences indicate that the earlier life stages are more sensitive than the adults to environmental stressors [15]. To compare the differential proteomic responses in the early life stages of mussels M. galloprovincialis, the D-shape larval and juvenile mussels were exposed to $\mathrm{Cd}$ with an environmentally relevant concentration $\left(50 \mu \mathrm{g} \mathrm{L}^{-1}\right)$ for $48 \mathrm{~h}$. The 2DE-based proteomics was conducted on the mussel samples to elucidate the differential biological effects of Cd in these two early life stages of mussels $M$. galloprovincialis.

\section{Materials and methods}

\subsection{Larvae breeding and experimental design}

Adult mussels M. galloprovincialis reached sexual maturity were collected in April 2015 from a pristine site (Yantai, China). All mussels were transported to the laboratory and acclimatized in aerated natural seawater (salinity $31 \mathrm{psu}$ ) at $21^{\circ} \mathrm{C}$ for 7 days. After acclimatization, these mussels were kept in air in dark place for $2 \mathrm{~h}$. Then each mussel was put into a beaker containing warmer seawater $\left(24{ }^{\circ} \mathrm{C}\right)$. After $2 \mathrm{~h}$, the majority of mussels came to ovulation and spermiation. The 500 mesh sieve screen was used to filter impurities. Then the sperms and eggs were quickly collected, respectively, to fertilize. All the fertilized eggs were then transferred into $50 \mathrm{~L}$ of normal filtered seawater (FSW) in a bucket. Continuous aeration was conducted during incubation. After approximately $48 \mathrm{~h}$, the majority of fertilized eggs developed into D-shape larvae (Fig. 1A). Then the D-shape larval mussels were divided into two groups (control and $\mathrm{Cd}$ exposure) each containing 6 buckets ( $30 \mathrm{~L}$ ) with a density of $\sim 25 \mathrm{D}$-shape larval mussels per milliliter. The environmentally relevant concentration $\left(50 \mu \mathrm{g} \mathrm{L}^{-1}\right)$ of $\mathrm{Cd}$ was selected for the exposures of D-shape larval mussels M. galloprovincialis. During the acclimatization and exposure periods, all the larvae were kept under a photoperiod of $12 \mathrm{~h}$ light and 12 h dark, and fed with the Chlorella vulgaris daily. After exposure for $48 \mathrm{~h}$, all the larvae ( 6.0-7.5 $\times 10^{5}$ individuals) from each two bucket were immediately filtered out by 500 mesh sieve screen and collected into one D-shape larval mussel sample. These D-shape larval mussel samples were quickly snap-frozen in liquid nitrogen and stored at $-80^{\circ} \mathrm{C}$.

Thirty juvenile mussels (length: $\sim 1.0 \mathrm{~cm}$, Fig. 1B) were purchased from local culturing farm in Yantai, China. After transported to the culture laboratory, the juvenile mussels were allowed to acclimate in aerated seawater $\left(21^{\circ} \mathrm{C}, 31 \mathrm{psu}\right.$, collected from pristine environment) in the laboratory for $7 \mathrm{~d}$ and fed with the Chlorella vulgaris Beij at a ration of $2 \%$ tissue dry weight daily. After acclimatization, the mussels were randomly divided into two groups (control and $\mathrm{Cd}$ exposure) containing fifteen individuals in $20 \mathrm{~L}$ of aerated seawater. The same concentration $\left(50 \mu \mathrm{g} \mathrm{L}^{-1}\right)$ of $\mathrm{Cd}$ was used for the exposure. After exposure for $48 \mathrm{~h}$, the whole soft tissues from juvenile mussels were dissected quickly. The samples of whole soft tissues were flash-frozen in liquid nitrogen and stored at $-80^{\circ} \mathrm{C}$ before further procedures. During the exposure periods, all the experimental conditions for juvenile mussels were completely identical to those for D-shape larval mussels.

\subsection{Protein extraction of mussel samples}

Total protein extraction was performed based on previous studies with some modifications [16,17]. Briefly, the mussel

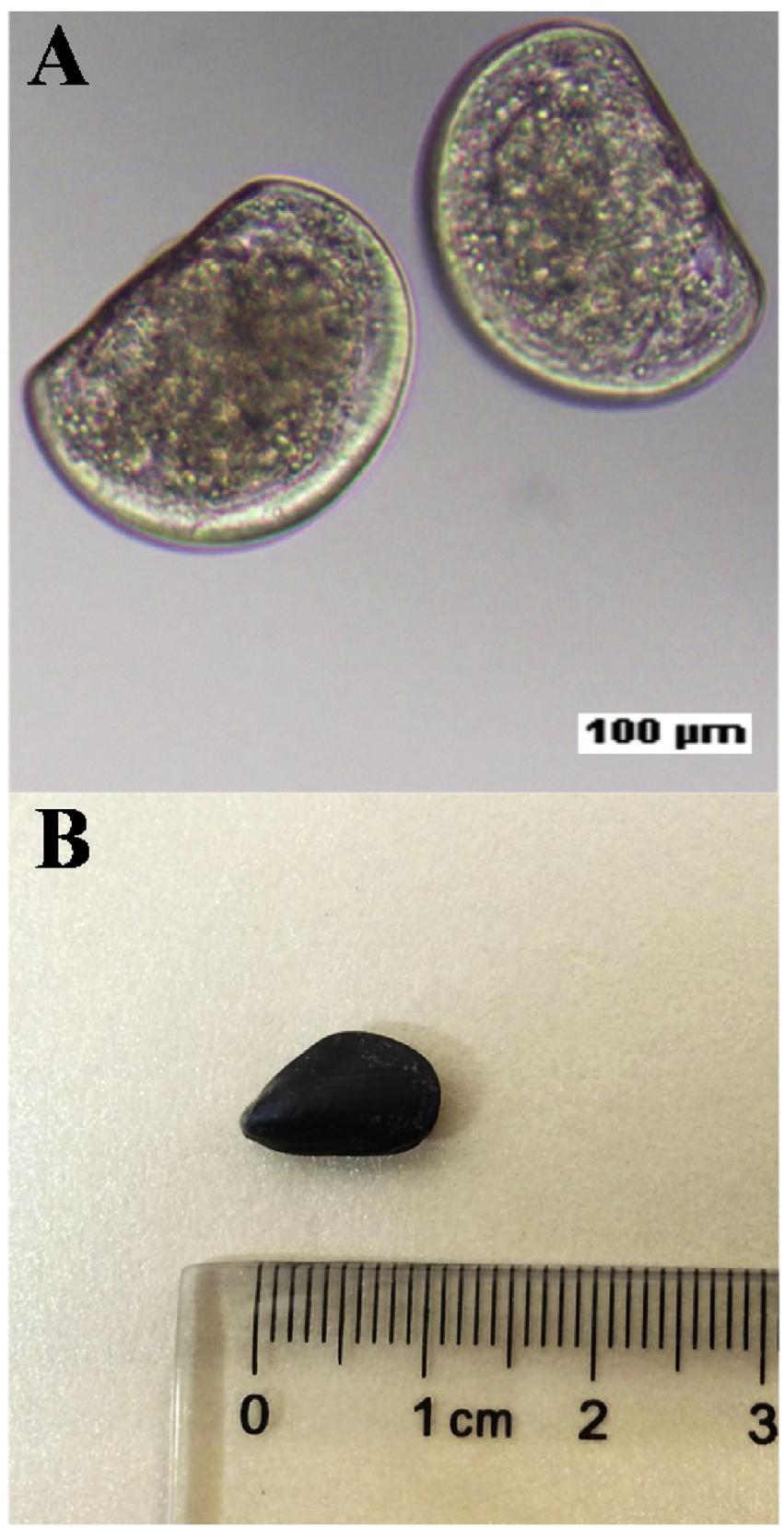

Fig. 1. The mussels M. galloprovincialis at early life stages used in this study, (A) Dshape larval and (B) juvenile.

samples were homogenized quickly on ice with $1 \mathrm{~mL}$ of TRIzol reagent and centrifuged at $12000 \mathrm{~g}$ for $5 \mathrm{~min}$ at $4{ }^{\circ} \mathrm{C}$. The supernatant was added with $200 \mu \mathrm{L}$ of chloroform before shaking vigorously for $3 \mathrm{~min}$ and precipitating for $3 \mathrm{~min}$. The mixture was centrifuged at $12000 \mathrm{~g}$ for $15 \mathrm{~min}$ at $4{ }^{\circ} \mathrm{C}$, and its upper aqueous layer was discarded. A volume of $300 \mu \mathrm{L}$ of absolute ethyl alcohol was added and the mixture was allowed to stand for $3 \mathrm{~min}$ at room temperature before being centrifuged at $2000 \mathrm{~g}$ for $5 \mathrm{~min}$ at $4{ }^{\circ} \mathrm{C}$. The phenol/ ethanol supernatant was precipitated for $30 \mathrm{~min}$ at room temperature by the addition of $750 \mu \mathrm{L}$ of isopropanol prior to centrifugation at $14000 \mathrm{~g}$ for $10 \mathrm{~min}$ at $4{ }^{\circ} \mathrm{C}$. The pellets were washed with $1 \mathrm{~mL}$ of ethanol (v/v 95\%) and centrifuged at $14000 \mathrm{~g}$ for $10 \mathrm{~min}$ at $4{ }^{\circ} \mathrm{C}$. This procedure was repeated twice. The pellets were solubilized in the lysis buffer (7 M urea; $2 \mathrm{M}$ thiourea; $4 \% \mathrm{~m} / \mathrm{V}$ CHAPS; $65 \mathrm{mM}$ DTT and 0.2\%W/V Bio-lyte buffer) and then incubated for 
$3 \mathrm{~h}$ at room temperature. The homogenate was centrifuged at $15000 \mathrm{~g}$ for $10 \mathrm{~min}$ and the supernatant was applied to electrophoresis. The total concentrations of proteins were determined by Protein Assay Kit of TianGen.

\subsection{Two-dimensional gel electrophoresis, image acquisition and data analysis}

For the first dimension (IEF), $130 \mu \mathrm{g}$ of protein was loaded onto IPG strips with a linear pH gradient from 4 to 7 (Immobiline Drystrip TM $24 \mathrm{~cm}$, GE Healthcare, USA) The isoelectric focusing gel solution ( $7 \mathrm{M}$ urea, $2 \mathrm{M}$ thiourea, 4\% m/v CHAPS, $65 \mathrm{mM}$ DTT, $0.001 \% \mathrm{~m} / \mathrm{v}$ bromophenol blue and 0.2\% W/V Bio-lyte buffer). IEF was conducted at $20^{\circ} \mathrm{C}$ with an Ettan IPGphor3 system for a total of $85858 \mathrm{Vh}$ (active rehydration was carried out at $30 \mathrm{~V}$ for $12 \mathrm{~h}$, followed by $100 \mathrm{~V}$ for $5 \mathrm{~h}, 500 \mathrm{~V}$ for $1 \mathrm{~h}, 1000 \mathrm{~V}$ for $1 \mathrm{~h}$, and a linear increase of voltage to $8000 \mathrm{~V}$ for $11 \mathrm{~h}$ and stand by $500 \mathrm{~V}$ for the second dimension).

After the first dimension, all the strips were placed in equilibration buffer $(0.05 \mathrm{M}$ Tris- $\mathrm{HCl}$, pH 8.8; $6 \mathrm{M}$ urea; 30\% glycerol; $2 \%$ $(\mathrm{w} / \mathrm{v})$ SDS; containing $1 \%(\mathrm{w} / \mathrm{v})$ DTT) and were slowly shaken for $15 \mathrm{~min}$. The strips were then incubated for another $15 \mathrm{~min}$ in the equilibration buffer with $2.5 \%(\mathrm{w} / \mathrm{v})$ iodoacetamide without DTT. The second dimension was conducted on $12.5 \%$ SDS-PAGE gels using the Ettan DALTsix system. After electrophoresis, the gels were silver stained by following the method of Mortz and Gharahdaghi $[18,19]$. Images were captured by ImageScanner III and spots were quantitatively analyzed using ImageMaster 2D Platinum 7.0. For all the matched spots, only protein spots with significant changes of at least 1.2-fold, and deemed significant by Student's $t$-test at a level of 95\% were accepted as differentially expressed proteins.

\subsection{In gel digestion and MS analysis}

In gel digestion was performed according to Katayama et al. [20]. After being completely dried, the samples were re-suspended with $5 \mu \mathrm{L}$ of $0.1 \%$ TFA followed by mixing in $1: 1$ ratio with a saturated solution of $\alpha$-cyano-4-hydroxy-trans-cinnamic acid in $50 \%$ acetonitrile [21]. One microliter of mixture was analyzed by an ABI 4800 MALDI-TOF/TOF Plus mass spectrometer (Applied Biosystems, Foster City, USA), data were acquired in a positive MS reflector using a CalMix5 standard to calibrate the instrument (ABI4800 Calibration Mixture). Both the MS and MS/MS data were integrated and processed using the GPS Explorer V3.6 software (Applied Biosystems, USA) with default parameters. Proteins were successfully identified based on $95 \%$ or higher confidence interval of their scores in the MASCOT V2.4 search engine (Matrix Science Ltd., London, U.K.). The following parameters were used in the search: NCBInr Metazoa (Animals) (2861494 sequences) database; trypsin as the digestion enzyme; one missed cleavage site; partial modifications of cysteine carbamidomethylation and methionine oxidization; no fixed modifications; $0.15 \mathrm{Da}$ for precursor ion tolerance and $0.25 \mathrm{Da}$ for fragment ion tolerance. Individual ions scores $>40$ indicate identity or extensive homology $(p<0.05)$.

\section{Results and discussion}

Proteomic responses were determined by 2DE-based proteomics in Cd-treated mussel samples at D-shape larval and juvenile stages, respectively (Fig. 2). A total of 16 spots resolved in 2DE gels were differentially expressed $(>1.2$ folds, $P<0.05)$. Fig. 2 reveals the differential protein spots in Cd-treated mussels M. galloprovincialis at D-shape larval and juvenile stages, respectively. For either Dshape larval mussels or juvenile mussels, all the differentially expressed proteins induced by $\mathrm{Cd}$ treatment in all three biological replicates of silver-stained gels were analyzed by MALDI-TOF/TOF mass spectrometry. The information of these proteins is summarized in Tables 1 and 2.

In Cd-treated D-shape larval mussel samples, a total of 8 protein spots were significantly differentially expressed, including 5 upregulated and 3 down-regulated proteins. These proteins were involved in protein homeostasis and immune defensive system (putative ubiquitin thioesterase, ubiquitin, 60S ribosomal protein L13A, ribosomal protein S7, DNA-directed RNA polymerase II and macrophage migration inhibitory factor), energy metabolism (triosephosphate isomerase) and detoxification (metallothionein). Eight differentially expressed proteins ( 4 up-regulated and 4 downregulated) were discovered in Cd-treated juvenile mussel samples. These proteins were related to immune and oxidative responses (apextrin-like protein, profilin and NADH dehydrogenase mitochondrial-like), protein translocation (signal sequence receptor beta-like protein) and signal transduction (peptidylprolyl isomerase A, guanine nucleotide-binding protein $G(0)$ subunit alpha, sorting nexin 6 and collagen alpha-6(VI) chain isoform X3).

In D-shape larval mussels, five proteins involved in protein homeostasis were found in response to $\mathrm{Cd}$ exposure. Both ubiquitin thioesterase and ubiquitin are regulatory proteins involved in the nonlysosomal degradation of intracellular proteins related to apoptosis induced by stressors [22]. In addition, ubiquitin-related proteins are responsive to immune and oxidative stress, which was observed in bacterial challenged mussel $M$. galloprovincialis and acute free radical-treated mussel Mytilus edulis [23,24]. Ribosomal proteins perform the crucial function of protein biosynthesis and have been also recognized as immunogenic proteins [23]. RNA polymerase II is responsible for the transcription of genes coding for protein in the nucleus [25]. Apparently, the alteration of these five proteins indicated that $\mathrm{Cd}$ exposure disturbed protein homeostasis and induced immune and oxidative stresses in D-shape larval mussels. Macrophage migration inhibitory factor is an evolutionarily ancient cytokine involved in the host immune response to stress and inflammation, which was confirmed in another marine bivalve, scallop Chlamys farreri [26]. This protein was down-regulated in D-shape larval mussels exposed to Cd, which suggested that $\mathrm{Cd}$ might inhibit the immune system in Dshape larval mussels. This finding is consistent with abovementioned immune stress induced by $\mathrm{Cd}$ in D-shape larval mussels. Triosephosphate isomerase is an essential enzyme playing an important role in the glycolysis for efficient energy production. The significant up-regulation of triosephosphate isomerase suggested the enhanced energy demand in Cd-treated D-shape larval mussels. Similarly, Cd exposure also significantly enhanced energy demand in adult green mussel Perna viridis resulting in reduced level of glucose [10]. Metallothioneins are low molecular proteins rich in SH groups with high affinity for binding heavy metal ions to detoxify the toxicity induced by heavy metals in animals [27]. Therefore, one metallothionein was significantly up-regulated in Dshape larval mussels.

In the Cd-treated juvenile mussels, interestingly, the proteomic responses were completely different compared with those in Cdtreated D-shape larval mussels, which demonstrated the differential responsive mechanisms to Cd exposure in the early life stages of mussels $M$. galloprovincialis. These differential responsive mechanisms may take into consideration behavioral, morphological, physiological and biochemical characteristics which should be different between life stages. Obviously, the D-shape larval and juvenile mussels have different characteristics, such as sizes, organ systems and the time taken for $\mathrm{Cd}$ to reach target sites, which might essentially perform differential responsive mechanisms to deal with Cd exposure. Apextrin has an important function in neutralization of pathogens and is immunologically responsive to 


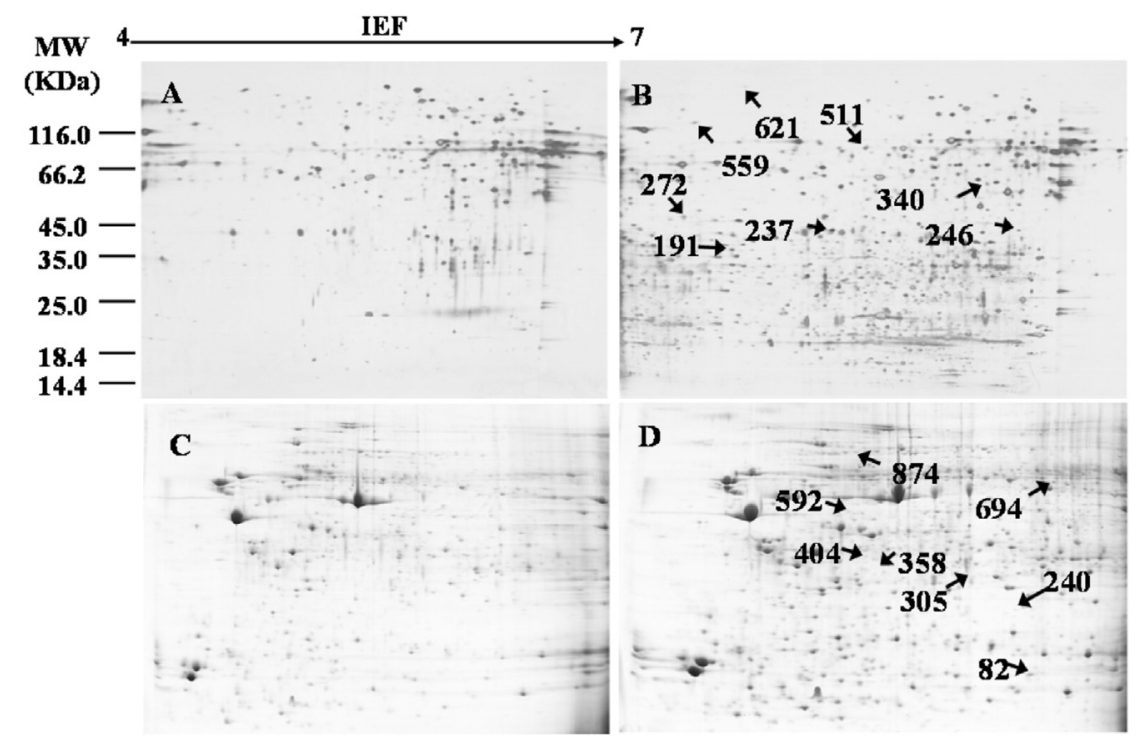

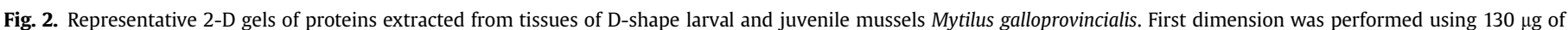

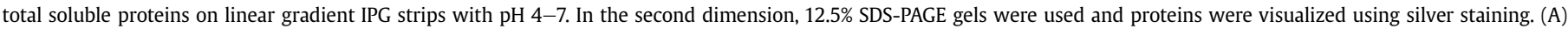

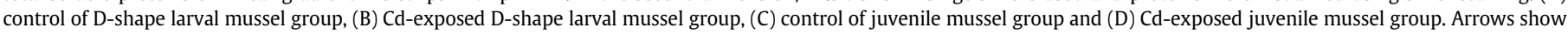
protein spots that changed significantly from $\mathrm{Cd}$-exposed groups compared to the control groups.

Table 1

List of protein spots that differentially expressed in D-shape larval mussels Mytilus galloprovincialis exposed to Cd (50 $\left.\mu \mathrm{g} \mathrm{L}{ }^{-1}\right)$.

\begin{tabular}{|c|c|c|c|c|c|c|c|c|c|}
\hline Match ID & Category and name ${ }^{b}$ & Species & gi number ${ }^{c}$ & $\mathrm{MW} / \mathrm{kDa}^{\mathrm{d}}$ & PI & Protein score $^{e}$ & $\mathrm{SC}^{\mathrm{f}}$ & $\mathrm{PN}^{g}$ & Ratio $^{\text {h }}$ \\
\hline 191 & Triosephosphate isomerase, partial & Mytilus edulis & 46909461 & 16.42 & 4.93 & 194 & $27 \%$ & 1 & 4.28 \\
\hline 237 & Putative ubiquitin thioesterase L96 & Crassostrea gigas & 405969289 & 189.30 & 5.07 & 40 & $10 \%$ & 1 & 4.10 \\
\hline 246 & 60 S ribosomal protein $\mathrm{L} 13 \mathrm{~A}$ & Mytilus edulis & 76573377 & 23.76 & 10.61 & 88 & $11 \%$ & 2 & 2.46 \\
\hline 272 & Ribosomal protein S7 & Argopecten irradians & 22758886 & 22.40 & 9.97 & 80 & $10 \%$ & 2 & 2.60 \\
\hline 340 & DNA-directed RNA polymerase II subunit RPB4 & Crassostrea gigas & 405964873 & 16.74 & 4.72 & 63 & $18 \%$ & 1 & 2.20 \\
\hline 511 & MT-10-IV = 10 kda class I metallothionein & Mytilus edulis & 455751 & 8.17 & 7.62 & 119 & $33 \%$ & 1 & -2.55 \\
\hline 559 & Macrophage migration inhibitory factor & Mytilus galloprovincialis & 344944171 & 12.76 & 6.28 & 44 & $8 \%$ & 1 & -2.97 \\
\hline 621 & Ubiquitin & Crassostrea hongkongensis & 283459000 & 15.02 & 9.94 & 72 & $17 \%$ & 2 & -4.86 \\
\hline
\end{tabular}

${ }^{\text {a }}$ Assigned spot ID as indicated in Fig. 2 .

b Identification of differentially expressed proteins in D-shape larval mussels M. galloprovincialis between control and Cd-exposed groups.

c Database accession numbers after searching against the NCBInr database.

d Experimental mass.

e Mascot score reported.

f Sequence coverage.

gumber of peptide sequences.

h Fold changes with significances $(>1.2$ folds and $p<0.05$ ) were calculated using ImageMaster 2D Platinum 7.0.

Table 2

List of protein spots that differentially expressed in juvenile mussels Mytilus galloprovincialis exposed to $\left.\mathrm{Cd}_{(50 \mu \mathrm{g} \mathrm{L}}^{-1}\right)$.

\begin{tabular}{|c|c|c|c|c|c|c|c|c|c|}
\hline Match ID ${ }^{\mathrm{a}}$ & Category and name ${ }^{\mathrm{b}}$ & Species & gi number ${ }^{c}$ & $\mathrm{MW} / \mathrm{kDa}^{\mathrm{d}}$ & PI & Protein score $e^{e}$ & $\mathrm{SC}^{\mathrm{f}}$ & $\mathrm{PN}^{\mathrm{g}}$ & Ratio $^{\mathrm{h}}$ \\
\hline 82 & Profilin & Crassostrea gigas & 405961157 & 26.96 & 8.81 & 336 & $24 \%$ & 2 & 1.22 \\
\hline 240 & Peptidylprolyl isomerase A, partial & Mytilus edulis & 672940978 & 21.74 & 5.77 & 562 & $28 \%$ & 3 & 1.55 \\
\hline 305 & Signal sequence receptor beta-like protein & Crassostrea gigas & 40643038 & 24.16 & 7.89 & 49 & $5 \%$ & 1 & -1.78 \\
\hline 358 & Apextrin-like protein & Mytilus galloprovincialis & 339785142 & 30.55 & 5.16 & 231 & $38 \%$ & 5 & -2.20 \\
\hline 404 & NADH dehydrogenase mitochondrial-like & Aplysia californica & 524911939 & 31.22 & 5.76 & 273 & $36 \%$ & 4 & 1.30 \\
\hline 592 & Guanine nucleotide-binding protein $\mathrm{G}(\mathrm{o})$ subunit alpha & Crassostrea gigas & 405970566 & 40.98 & 5.22 & 235 & $17 \%$ & 4 & -1.30 \\
\hline 694 & Sorting nexin 6 & Crassostrea gigas & 405952237 & 31.11 & 5.16 & 503 & $42 \%$ & 5 & 1.74 \\
\hline 874 & Collagen alpha- $6(\mathrm{VI})$ chain isoform $\mathrm{X} 3$ & Papio anubis & 685527479 & 28.05 & 4.90 & 475 & $30 \%$ & 4 & -1.31 \\
\hline
\end{tabular}

a Assigned spot ID as indicated in Fig. 2.

b Identification of differentially expressed proteins in juvenile mussels M. galloprovincialis between control and Cd-exposed groups.

c Database accession numbers after searching against the NCBInr database.

d Experimental mass.

e Mascot score reported.

f Sequence coverage.

g Number of peptide sequences.

${ }^{\mathrm{h}}$ Fold changes with significances $(>1.2$ folds and $p<0.05)$ were calculated using ImageMaster 2D Platinum 7.0. 
pathogens [28]. In Cd-treated juvenile mussels, one downregulated apextrin-like protein suggested that $\mathrm{Cd}$ exposure might inhibit the immune system in juvenile mussels. Profilin is thought to regulate actin polymerization in response to extracellular signals. As a flavoprotein, NADH dehydrogenase contains iron-sulfur centers and is involved in production of reactive oxygen species in mitochondria [29]. These two proteins, profilin and NADH dehydrogenase, are known to be related to oxidative stress $[29,30]$. Therefore, the alteration of profilin and NADH dehydrogenase confirmed the oxidative stress induced by $\mathrm{Cd}$ in juvenile mussels. Previous studies suggested that signal sequence receptor played a role in protein translocation across the endoplasmic reticulum membrane [31]. However, a subsequent study indicated that signal sequence receptor was either not required for protein translocation or was one of a family of functionally redundant components [32]. Therefore, the reason to explain the down-regulation of signal sequence receptor in Cd-treated juvenile mussels remains unclear. Surprisingly, four proteins (peptidylprolyl isomerase A, guanine nucleotide-binding protein $\mathrm{G}(\mathrm{o})$ subunit alpha, sorting nexin 6 and collagen alpha-6(VI) chain isoform X3) involved in signal transduction were significantly altered in Cd-treated juvenile mussels. Among these four proteins, guanine nucleotide-binding protein plays an important role in immune functions [33]. The downregulation of this protein confirmed the immune stress induced by $\mathrm{Cd}$ in juvenile mussels, as marked by the down-regulated apextrin-like protein. Peptidylprolyl isomerase A, sorting nexin 6 and collagen alpha- $6(\mathrm{VI})$ chain isoform $\mathrm{X} 3$ are known proteins recognized as the markers of apoptosis $[30,34,35]$. The alterations of these three proteins suggested that $\mathrm{Cd}$ exposure caused apoptosis in juvenile mussels.

In summary, the biological effects of an environmentally relevant concentration of $\mathrm{Cd}\left(50 \mu \mathrm{g} \mathrm{L}^{-1}\right)$ were characterized in the early life stages (D-shape larval and juvenile) of marine mussels M. galloprovincialis using 2DE-based proteomics. Basically, the different proteomic responses demonstrated the differential responsive mechanisms in the early life stages of mussels treated with $\mathrm{Cd}$. In details, results indicated that Cd mainly induced immune and oxidative stresses in both D-shape larval and juvenile mussels via different pathways. The significant up-regulation of triosephosphate isomerase and metallothionein confirmed the enhanced energy demand and mobilized detoxification mechanism in D-shape larval mussels exposed Cd. In juvenile mussels, Cd exposure also induced clear apoptosis. Overall, this work suggests that $\mathrm{Cd}$ is a potential immune toxicant to mussel M. galloprovincialis at early life stages because of their immature immune systems.

\section{Acknowledgments}

This work was supported by National Key Basic Research Program of China (2015CB453303), Key Project from National Natural Science Foundation of China (21237004) and Natural Science Foundation of Shandong Province (No. JQ201310).

\section{References}

[1] Q. Sun, J. Song, Y. Gao, J. Chen, Y. Sheng, Distribution of heavy metals speciation and pollution in surface sediment from typical ecologically regions of Yantai coastal zone (in Chinese), Mar. Sci. 34 (2011) 31-36.

[2] C. Ji, D. Yu, Q. Wang, F. Li, J. Zhao, H. Wu, Impact of metal pollution on shrimp Crangon affinis by NMR-based metabolomics, Mar. Pollut. Bullet. 106 (2016) $372-376$.

[3] R. Company, A. Serafim, M.J. Bebianno, R. Cosson, B. Shillito, A. Fiala-Médioni, Effect of cadmium, copper and mercury on antioxidant enzyme activities and lipid peroxidation on the gills of the hydrothermal vent mussel Bathymodiolus axoricus, Mar. Environ. Res. 58 (2004) 377-381.

[4] C. Ji, H. Wu, M. Zhou, J. Zhao, Multiple biomarkers of biological effects induced by cadmium in clam Ruditapes philippinarum, Fish Shellfish Immunol. 44 (2015) 430-435.
[5] A. Elbaz, Y.Y. Wei, Q. Meng, Q. Zheng, Z.M. Yang, Mercury-induced oxidative stress and impact on antioxidant enzymes in Chlamydomonas reinhardtii, Ecotoxicology 19 (2010) 1285-1293.

[6] V. Matozzo, A. Tomei, M. Marin, Acetylcholinesterase as a biomarker of exposure to neurotoxic compounds in the clam Tapes philippinarum from the Lagoon of Venice, Mar. Pollut. Bullet. 50 (2005) 1686-1693.

[7] O.A.H. Jones, F. Dondero, A. Viarengo, J.L. Griffin, Metabolic profiling of Mytilus galloprovincialis and its potential applications for pollution assessment, Mar. Ecol. Prog. Ser. 369 (2008) 169-179.

[8] C. Ji, H. Wu, L. Wei, J. Zhao, J. Yu, Proteomic and metabolomic analysis revea gender-specific responses of mussel Mytilus galloprovincialis to 2,2',4,4'-tetrabromodiphenyl ether (BDE 47), Aquat. Toxicol. 140-141 (2013) 449-457.

[9] C. Ji, H. Wu, L. Wei, J. Zhao, Q. Wang, H. Lu, Responses of Mytilus galloprovincialis to bacterial challenges by metabolomics and proteomics, Fish Shellfish Immunol. 35 (2013) 489-498.

[10] H. Wu, W.-X. Wang, Tissue-specific toxicological effects of cadmium in green mussel (Perna viridis): nuclear magnetic resonance-based metabolomics study, Environ. Toxicol. Chem. 30 (2011) 806-812.

[11] X. Liu, C. Yang, L. Zhang, L. Li, S. Liu, J. Yu, et al., Metabolic profiling of cadmium-induced effects in one pioneer intertidal halophyte Suaeda salsa by NMR-based metabolomics, Ecotoxicology 20 (2011) 1422-1432.

[12] J.-W. Choi, H. Liu, H. Song, J.H.Y. Park, J.W. Yun, Plasma marker proteins associated with the progression of lung cancer in obese mice fed a high-fat diet, Proteomics 12 (2012) 1999-2013.

[13] N. Ahsan, J. Renaut, S. Komatsu, Recent developments in the application of proteomics to the analysis of plant responses to heavy metals, Proteomics 9 (2009) 2602-2621.

[14] A. Jernelov, The international mussel watch: a global assessment of environmental levels of chemical contaminants, Sci. Total Environ. 188 (1996) S37-S44.

[15] D. Behrens, J. Rouxel, T. Burgeot, F. Akcha, Comparative embryotoxicity and genotoxicity of the herbicide diuron and its metabolites in early life stages of Crassostrea gigas: implication of reactive oxygen species production, Aquat. Toxicol. 175 (2016) 249-259.

[16] P.A. Kirkland, J. Busby, S. Stevens Jr., J.A. Maupin-Furlow, Trizol-based method for sample preparation and isoelectric focusing of halophilic proteins, Anal. Biochem. 351 (2006) 254-259.

[17] F.W.-F. Lee, S.C.-L. Lo, The use of Trizol reagent (phenol/guanidine isothiocyanate) for producing high quality two-dimensional gel electrophoretograms (2-DE) of dinoflagellates, J. Microbiol. Meth. 73 (2008) 26-32.

[18] E. Mortz, T.N. Krogh, H. Vorum, A. Gorg, Improved silver staining protocols for high sensitivity protein identification using matrix-assisted laser desorption/ ionization-time of flight analysis, Proteomics 1 (2001) 1359-1363.

[19] F. Gharahdaghi, C.R. Weinberg, D.A. Meagher, S.M. Mische, Mass spectrometric identification of proteins from silver-stained polyacrylamide gel: a method for the removal of silver ions to enhance sensitivity, Electrophoresis 20 (1999) 601-605.

[20] H. Katayama, T. Nagasu, Y. Oda, Improvement of in-gel digestion protocol for peptide mass fingerprinting by matrix-assisted laser desorption/ionization time-of-flight mass spectrometry, Rapid Commun. Mass Spectrom. 15 (2001) 1416-1421.

[21] A. Shevchenko, M. Wilm, O. Vorm, M. Mann, Mass spectrometric sequencing of proteins from silver-stained polyacrylamide gels, Anal. Chem. 68 (1996) 850-858.

[22] Y. Kimura, K. Tanaka, Regulatory mechanisms involved in the control of ubiquitin homeostasis, J. Biochem. 147 (2010) 793-798.

[23] H. Wu, C. Ji, L. Wei, J. Zhao, H. Lu, Proteomic and metabolomic responses in hepatopancreas of Mytilus galloprovincialis challenged by Micrococcus luteus and Vibrio anguillarum, J. Proteomics 94 (2013) 54-67.

[24] B. McDonagh, D. Sheehan, Redox proteomics in the blue mussel Mytilus edulis: carbonylation is not a pre-requisite for ubiquitination in acute free radicalmediated oxidative stress, Aquat. Toxicol. 79 (2006) 325-333.

[25] B.W. Baer, D. Rhodes, Eukaryotic RNA polymerase II binds to nucleosome cores from transcribed genes, Nature 301 (1983) 482-488.

[26] F. Li, S. Huang, L. Wang, J. Yang, H. Zhang, L. Qiu, et al., A macrophage migration inhibitory factor like gene from scallop Chlamys farreri: involvement in immune response and wound healing, Dev. Comp. Immunol. 35 (2011) 62-71.

[27] M.J. Bebianno, M.A. Serafim, Comparison of metallothionein induction in response to cadmium in the gills of the bivalve mollusks Mytilus galloprovincialis and Ruditapes decussates, Sci. Total Environ. 214 (1998) 123-131.

[28] N.M. Dheilly, P.A. Haynes, U. Bove, S.V. Nair, D.A. Raftos, Comparative proteomic analysis of a sea urchin (Heliocidaris erythrogramma) antibacterial response revealed the involvement of apextrin and calreticulin, J. Inverteb. Pathol. 106 (2011) 223-229.

[29] E. Abele, E. Philip, P.M. Gonzalez, S. Puntarulo, Marine invertebrate mitochondria and oxidative stress, Front. Biosci. 12 (2007) 933-946.

[30] C. Ji, H. Wu, L. Wei, J. Zhao, iTRAQ-based quantitative proteomic analyses on the gender-specific responses in mussel Mytilus galloprovincialis to tetrabromobisphenol A, Aquat. Toxicol. 157 (2014) 30-40.

[31] S. Prehn, J. Herz, E. Hartmann, T.V. Kurzchalia, R. Frank, K. Roemisch, et al., Structure and biosynthesis of the signal-sequence receptor, Eur. J. Biochem. 188 (1990) 439-445.

[32] G. Migliaccio, C.V. Nicchitta, G. Blobel, The signal sequence receptor, unlike the signal recognition particle receptor, is not essential for protein translocation, 
J. Cell Biol. 117 (1992) 15-25.

[33] S. Herroeder, P. Reichardt, A. Sassmann, B. Zimmermann, D. Jaeneke, J. Hoeckner, et al., Guanine nucleotide-binding proteins of the G12 family shape immune functions by controlling $\mathrm{CD} 4+\mathrm{T}$ cell adhesiveness and motility, Immunity 30 (2009) 708-720.

[34] W. Yuan, J. Yan, Y. Liang, J. Wu, Z. Wang, C. Wang, Antiapoptotic and proapoptotic signaling of cyclophilin A in endothelial cells, Inflammation 36 (2013) 567-572.

[35] N. Lu, Q. Shen, T.R. Mahoney, X. Liu, Z. Zhou, Three sorting nexins drive the degradation of apoptotic cells in response to PtdIns(3)P signaling, Mol. Biol. Cell 22 (2011) 354-374. 